\title{
gFinder: a web-based bioinformatics tool for the analysis of
}

\section{$N$-glycopeptides}

\author{
Ju-Wan Kim ${ }^{1,2}$, Heeyoun Hwang ${ }^{3}$, Jong-Sun Lim², Hyoung-Joo Lee ${ }^{2}$, Seul-Ki Jeong ${ }^{2}$, Jong Shin Yoo and \\ Young-Ki Paik ${ }^{1,2 *}$
}

${ }^{1}$ Graduate Program in Functional Genomics, College of Life Sciences and Biotechnology, Yonsei University, Seoul, 03722, Korea, ${ }^{2}$ Yonsei Proteome Research Center, Seoul, 03722, Korea, ${ }^{3}$ Korea Basic Science Institute, Ochang, 28199, Chungbuk, Korea

*To whom correspondence should be addressed to:

Room 423, Industry-Academic Cooperation Building, Yonsei Proteome Research Center,

Yonsei University, 50 Yonsei-Ro, Sudaemoon-ku, Seoul, 03722, Korea

Phone: +82-2-2123-4242; Fax: +82-2-393-6589; E-mail: paikyk@yonsei.ac.kr 
Table S1. Results of human plasma (normal) analysis by gFinder

\begin{tabular}{|c|c|c|c|c|}
\hline Glycan & Structure & $\begin{array}{c}\text { Precursor } \\
\text { Mass }^{\mathrm{a}}\end{array}$ & $\mathbf{R T}^{\mathbf{b}}$ & ppm \\
\hline \multicolumn{5}{|c|}{ NN*ATVHEQVGGPSLTSDLQAQSK } \\
\hline$[\mathrm{HexNAc}] 4[\mathrm{Hex}] 5[\mathrm{NeuAc}] 2$ & $\stackrel{-\infty}{-\infty}$ & $\begin{array}{l}1529.32(+3) \\
1147.24(+4)\end{array}$ & $\begin{array}{l}63.62 \\
63.61\end{array}$ & $\begin{array}{l}3.10 \\
1.98\end{array}$ \\
\hline \multicolumn{5}{|l|}{$\mathbf{N}^{*}$ GSLFAFR } \\
\hline [HexNAc]3[Hex]5[NeuAc]1 & & $\begin{array}{c}1311.54(+2) \\
874.69(+3)\end{array}$ & $\begin{array}{l}69.11 \\
69.13\end{array}$ & $\begin{array}{l}3.27 \\
2.60\end{array}$ \\
\hline [HexNAc]4[Hex]5[NeuAc]1 & ond & $\begin{array}{c}1413.08(+2) \\
942.39(+3)\end{array}$ & $\begin{array}{l}68.87 \\
68.86\end{array}$ & $\begin{array}{l}2.82 \\
2.90\end{array}$ \\
\hline$[\mathrm{HexNAc}] 4[\mathrm{Hex}] 5[\mathrm{NeuAc}] 2$ & 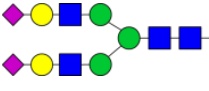 & $1039.42(+3)$ & 71.13 & 3.79 \\
\hline [HexNAc]5[Hex]6[NeuAc]3 & =10 & $1258.16(+3)$ & 71.42 & 2.07 \\
\hline
\end{tabular}

* $N$-glycosylation site

${ }^{a}$ mass unit:Da, charge state in bracket, ${ }^{b} \mathrm{~min}$

mannose, $\bigcirc$ galactose, $\mathrm{N}$-acetylglucosamine, $\boldsymbol{\Delta}$ fucose, $\diamond \mathrm{N}$-acetylneuraminic acid (glycan symbols follow CFG nomenclature).

Table S2. Results of human plasma (HCC) analysis by gFinder

\begin{tabular}{|c|c|c|c|c|}
\hline Glycan (HCC) & Structure & $\begin{array}{c}\text { Precursor } \\
\text { Mass }^{\mathbf{a}}\end{array}$ & $\mathbf{R T}^{\mathbf{b}}$ & ppm \\
\hline \multicolumn{5}{|c|}{ NN*ATVHEQVGGPSLTSDLQAQSK } \\
\hline [HexNAc]4[Hex $] 5[\mathrm{NeuAc}] 2$ & & $1147.74(+4)$ & 62.03 & 3.63 \\
\hline [HexNAc]5[Hex]6[NeuAc]3[Fuc]1 & 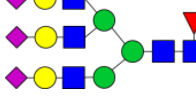 & $1347.81(+4)$ & 62.83 & 2.35 \\
\hline \multicolumn{5}{|l|}{$\mathbf{N}^{*}$ GSLFAFR } \\
\hline$[\mathrm{HexNAc}] 3[\mathrm{Hex}] 4[\mathrm{NeuAc}] 1$ & & $1230.51(+2)$ & 69.34 & 1.86 \\
\hline [HexNAc]3[Hex $] 5[\mathrm{NeuAc}] 1$ & oc & $\begin{array}{c}1311.54(+2) \\
874.70(+3)\end{array}$ & $\begin{array}{l}68.00 \\
68.05\end{array}$ & $\begin{array}{l}2.66 \\
2.71\end{array}$ \\
\hline [HexNAc]3[Hex]6[NeuAc]1 & & $1392.57(+2)$ & 68.96 & 4.30 \\
\hline$[\mathrm{HexNAc}] 4[\mathrm{Hex}] 5[\mathrm{NeuAc}] 1$ & Ol & $942.39(+3)$ & 67.77 & 2.37 \\
\hline
\end{tabular}




\begin{tabular}{|c|c|c|c|c|}
\hline [HexNAc]4[Hex $] 5[\mathrm{NeuAc}] 2$ & - & $1039.42(+3)$ & 69.79 & 3.21 \\
\hline [HexNAc]5[Hex]6[NeuAc]3 & 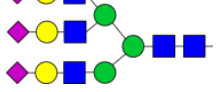 & $1258.16(+3)$ & 71.68 & 3.66 \\
\hline [HexNAc]5[Hex]6[NeuAc]3[Fuc]1 & & $1306.85(+3)$ & 71.24 & 2.48 \\
\hline
\end{tabular}

* $N$-glycosylation site

${ }^{a}$ mass unit:Da, charge state in bracket, ${ }^{b} \mathrm{~min}$

$\checkmark$ mannose, $\bigcirc$ galactose, $\mathrm{N}$-acetylglucosamine, $\boldsymbol{\Delta}$ fucose, $\diamond \mathrm{N}$-acetylneuraminic acid (glycan symbols follow CFG nomenclature). 
Table S3. b/y ion match score of missing protein backbone sequence

\begin{tabular}{ccccc}
\hline Sequence & ID & Position & N-site & yScore \\
\hline TALQGATQRSQMANSSR & Q8N9B8 & $358-374$ & 371 & 4 \\
ENVSMMMLGPQTLSIR & Q8N9V7 & $733-748$ & 734 & 1 \\
EWTFVIENESPSGRR & Q8NDI1 & $97-111$ & 104 & 1 \\
MKGETPVNSTMSIGQAR & P63215 & $1-17$ & 8 & 1 \\
MTEELEALRNSSLGTR & Q5VT25 & $845-860$ & 854 & 3 \\
QSLQNCQNLSKDLMK & Q3V6T2 & $519-533$ & 526 & 1 \\
YRSQHLDNFSNQIGK & P12259 & $375-389$ & 382 & 3 \\
\hline
\end{tabular}

Table S4. b/y ion match table of TALQGATQRSQMANSSR

\begin{tabular}{ccccccc}
\hline $\mathrm{b}+$ & $\mathrm{b} 2+$ & $\#$ & $\mathrm{Seq}$ & $\#$ & $\mathrm{y}+$ & $\mathrm{y} 2+$ \\
\hline 102.0550 & 51.5311 & 1 & $\mathrm{~T}$ & 17 & & \\
173.0921 & 87.0497 & 2 & $\mathrm{~A}$ & 16 & 1705.8398 & 853.4236 \\
286.1761 & 143.5917 & 3 & $\mathrm{~L}$ & 15 & 1634.8027 & 817.9050 \\
414.2347 & 207.6210 & 4 & $\mathrm{Q}$ & 14 & 1521.7187 & 761.3630 \\
471.2562 & 236.1317 & 5 & $\mathrm{G}$ & 13 & 1393.6601 & 697.3337 \\
542.2933 & 271.6503 & 6 & $\mathrm{~A}$ & 12 & 1336.6386 & 668.8229 \\
643.3410 & 322.1741 & 7 & $\mathrm{~T}$ & 11 & 1265.6015 & 633.3044 \\
771.3995 & 386.2034 & 8 & $\mathrm{Q}$ & 10 & 1164.5538 & 582.7806 \\
927.5007 & 464.2540 & 9 & $\mathrm{R}$ & 9 & 1036.4953 & 518.7513 \\
1014.5327 & 507.7700 & 10 & $\mathrm{~S}$ & 8 & 880.3941 & 440.7007 \\
1142.5913 & 571.7993 & 11 & $\mathrm{Q}$ & 7 & 793.3621 & 397.1847 \\
1273.6317 & 637.3195 & 12 & $\mathrm{M}$ & 6 & 665.3035 & 333.1554 \\
1344.6689 & 672.8381 & 13 & $\mathrm{~A}$ & 5 & 534.2630 & 267.6352 \\
1458.7118 & 729.8595 & 14 & $\mathrm{~N}$ & 4 & 463.2259 & 232.1166 \\
1545.7438 & 773.3755 & 15 & $\mathrm{~S}$ & 3 & 349.1830 & 175.0951 \\
1632.7758 & 816.8916 & 16 & $\mathrm{~S}$ & 2 & 262.1510 & 131.5791 \\
\hline & & 17 & $\mathrm{R}$ & 1 & 175.1190 & 88.0631 \\
\hline
\end{tabular}




\section{Figure S1}

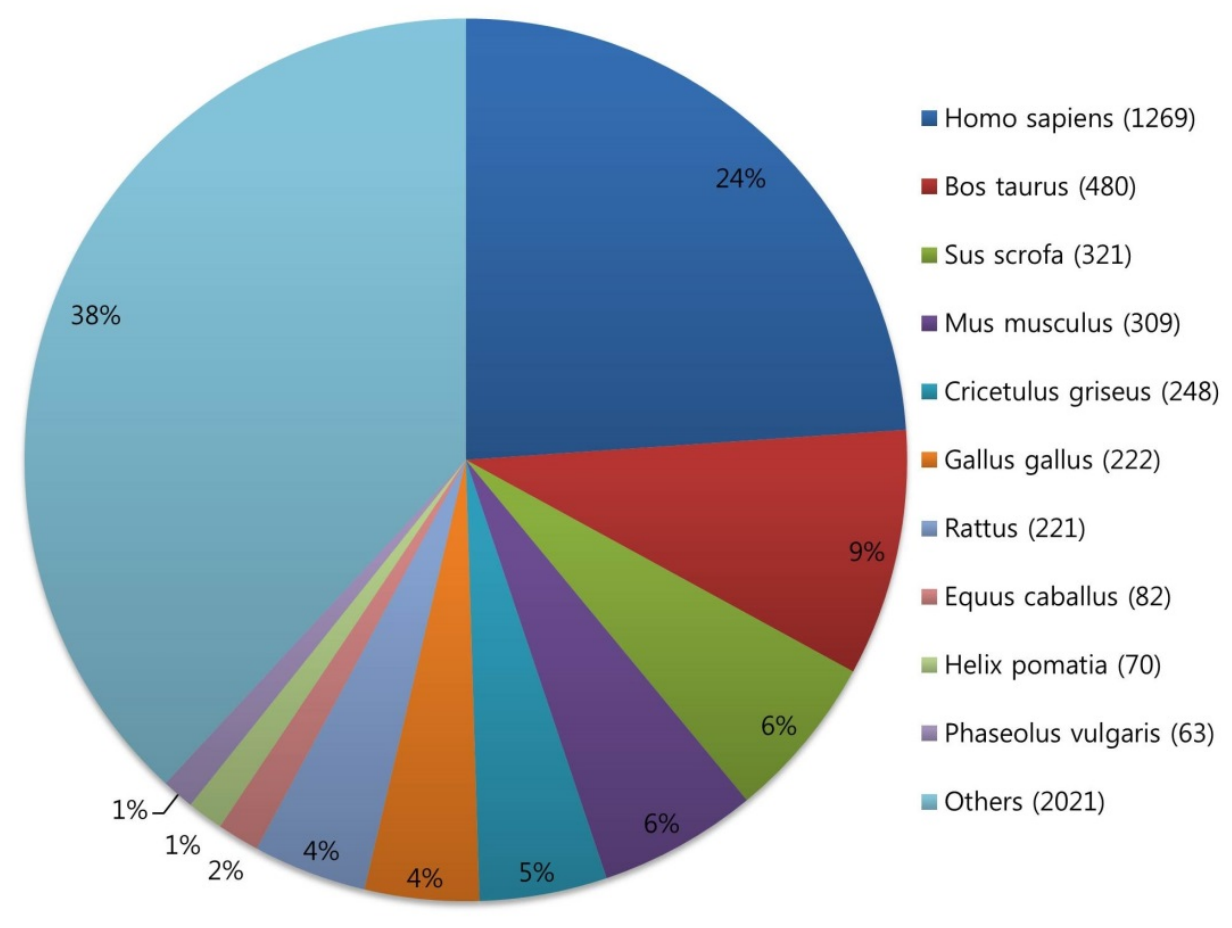

Figure S1. Frequency distribution of carbohydrates in the top 10 taxonomic categories. The pie charts show the frequency distribution (\%) of the top 10 taxonomic categories in N-linked glycan of the GlycomeDB. 
Figure S2

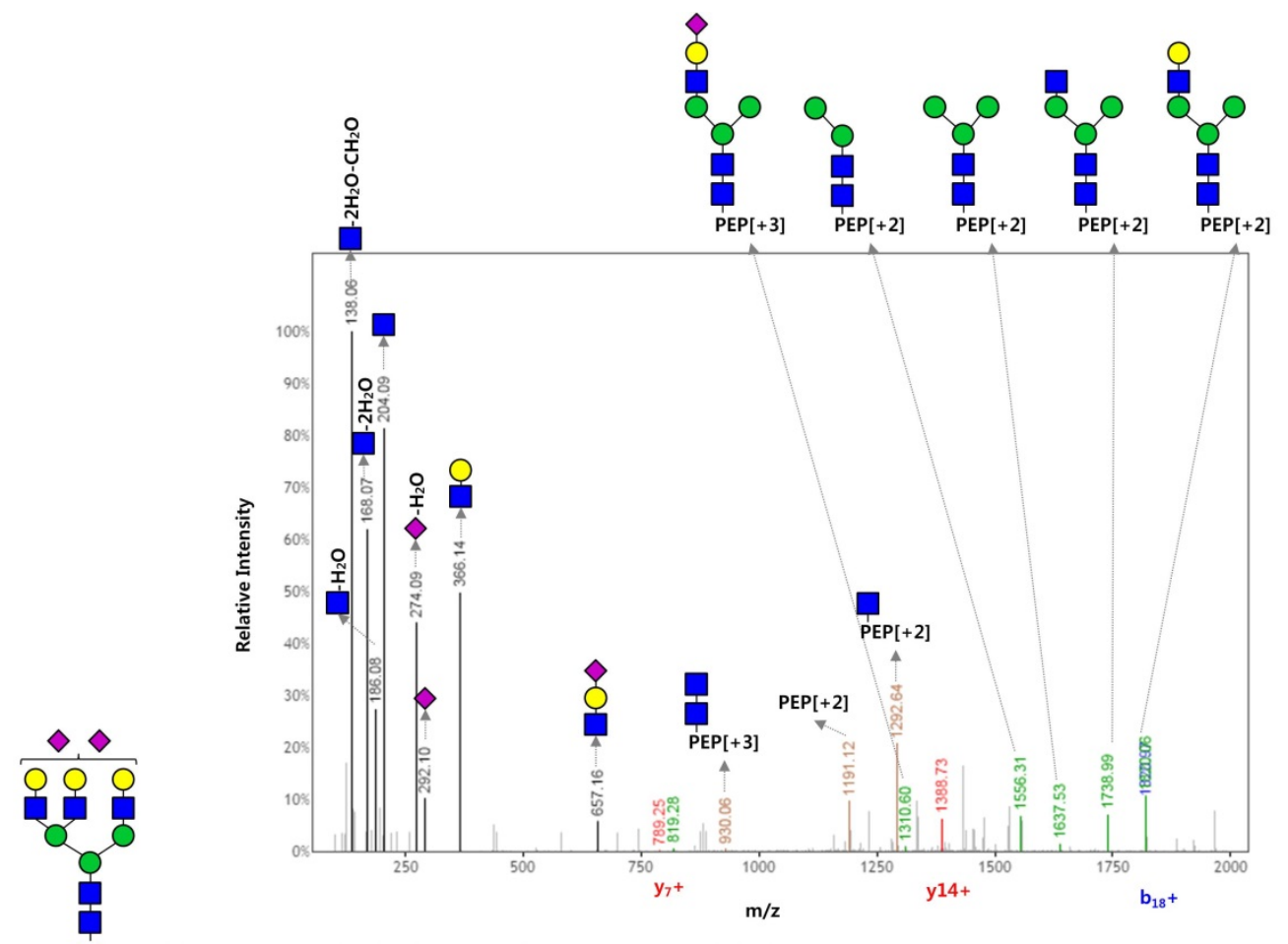

NNATVHEQVGGPSLTSDLQAQSK (m/z 1238.52 4+)

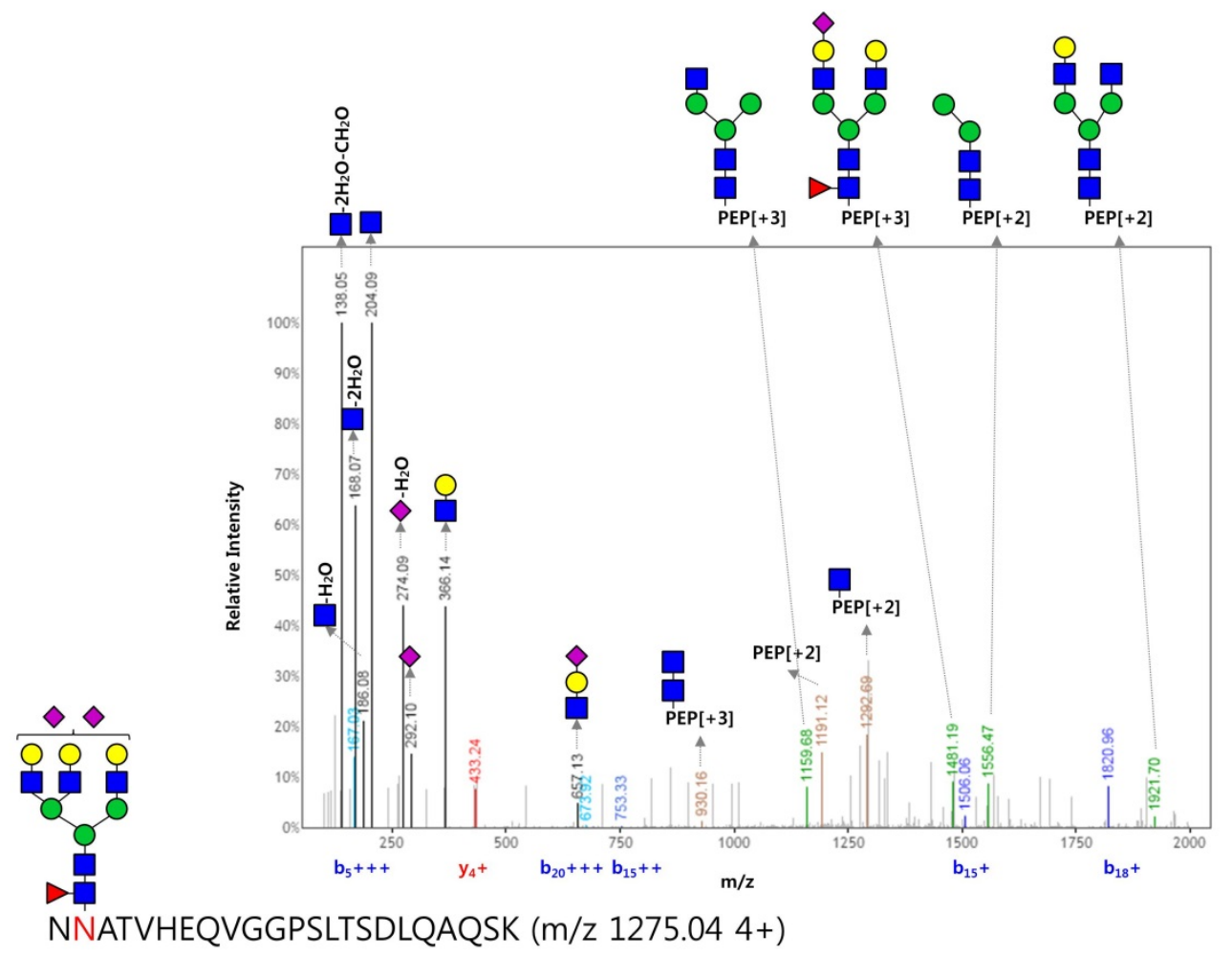




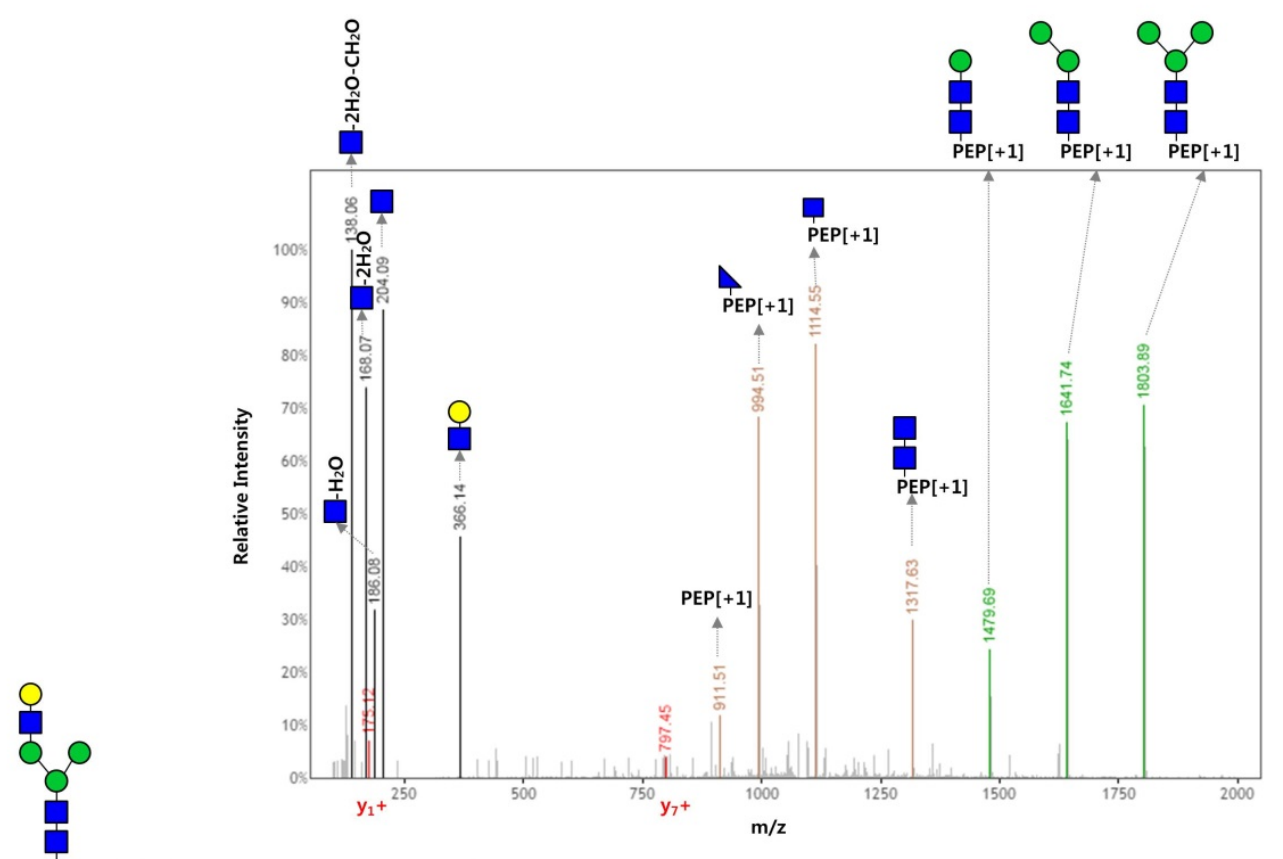

NGSLFAFR (m/z 1084.96 2+)

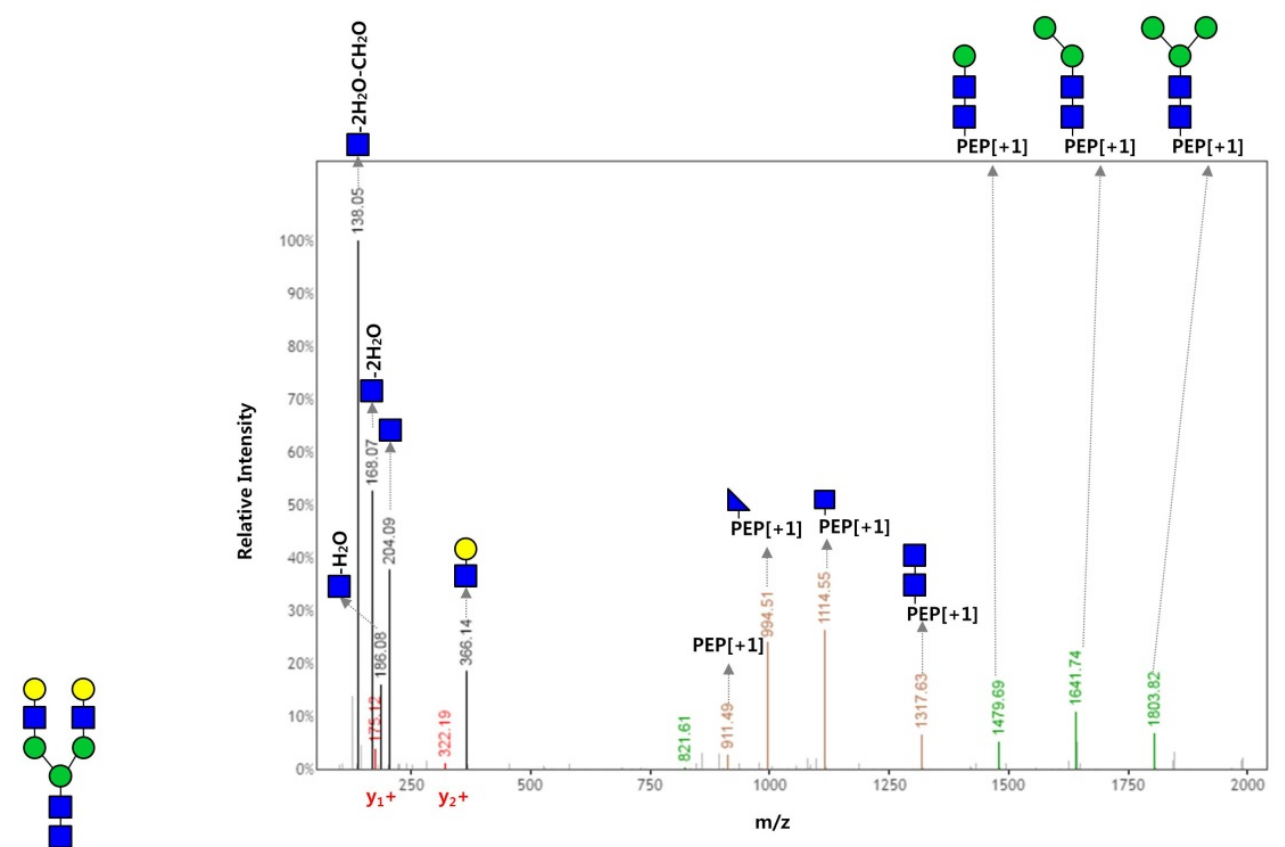

NGSLFAFR (m/z $1267.532+)$ 


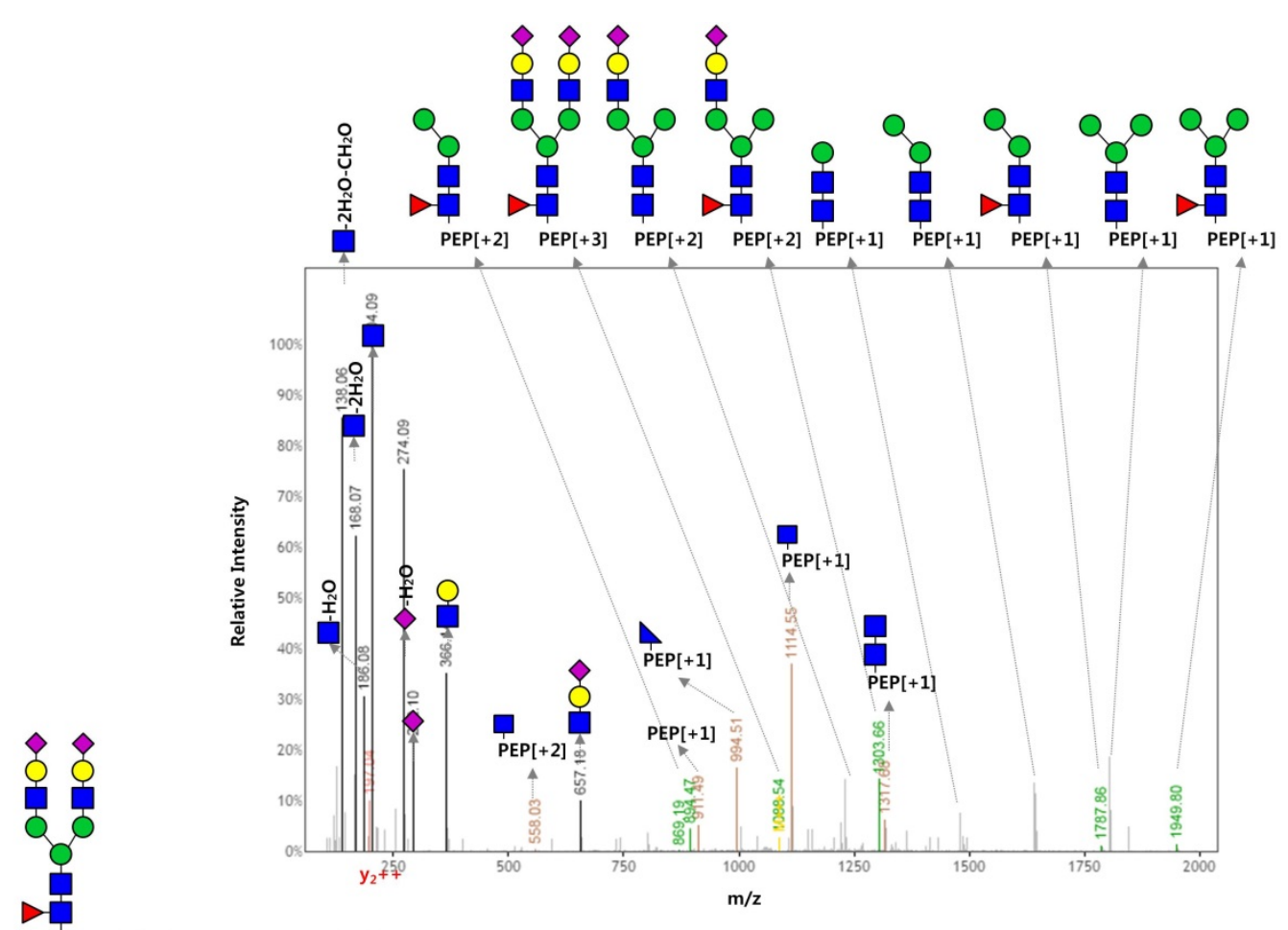

NGSLFAFR (m/z 996.40 3+)

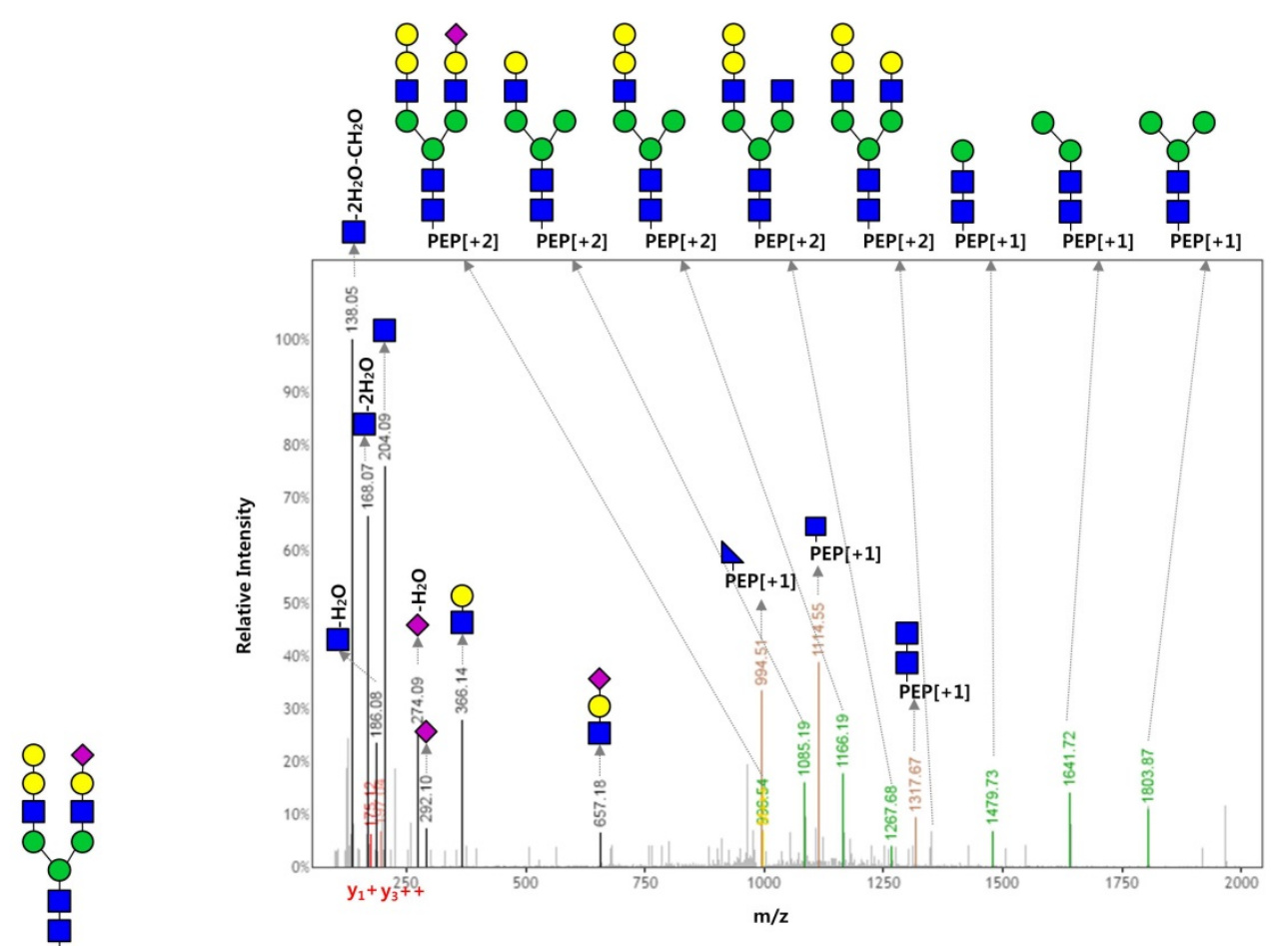

NGSLFAFR (m/z $996.403+$ ) 


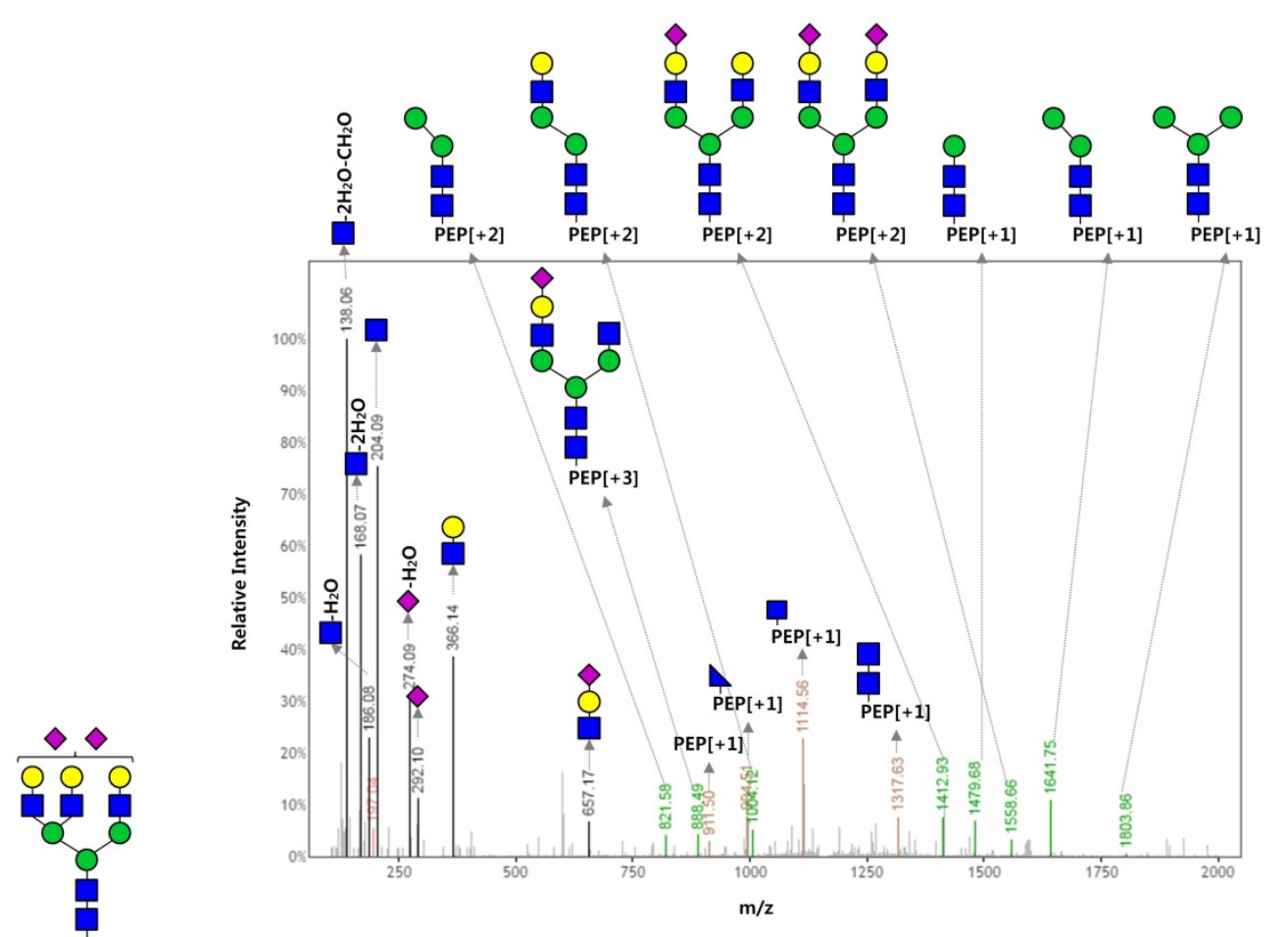

NGSLFAFR (m/z 1161.13 3+)

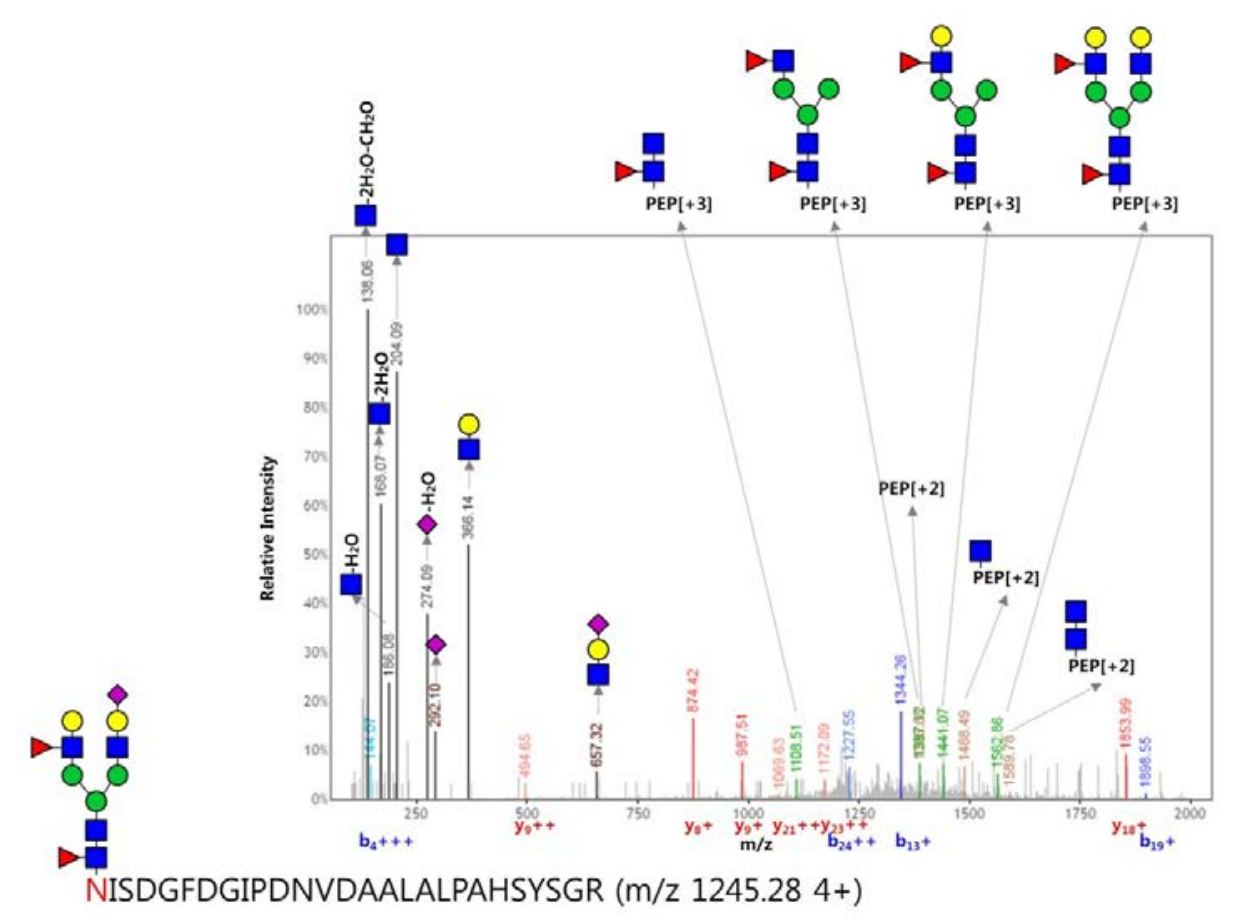

Figure S2. Eight newly identified $N$-glycopeptides of the vitronectin standard. Glycan symbols follow CFG nomenclature. $\quad \mathbf{~ m e a n s ~ c r o s s - r i n g ~ c l e a v a g e ~ f r a g m e n t s ~ o f ~ G l c N A c ~ w i t h ~ a ~ l o s s ~ o f ~ 1 2 0 . 0 4 2 3 ~ D a . ~}$ 
Figure S3
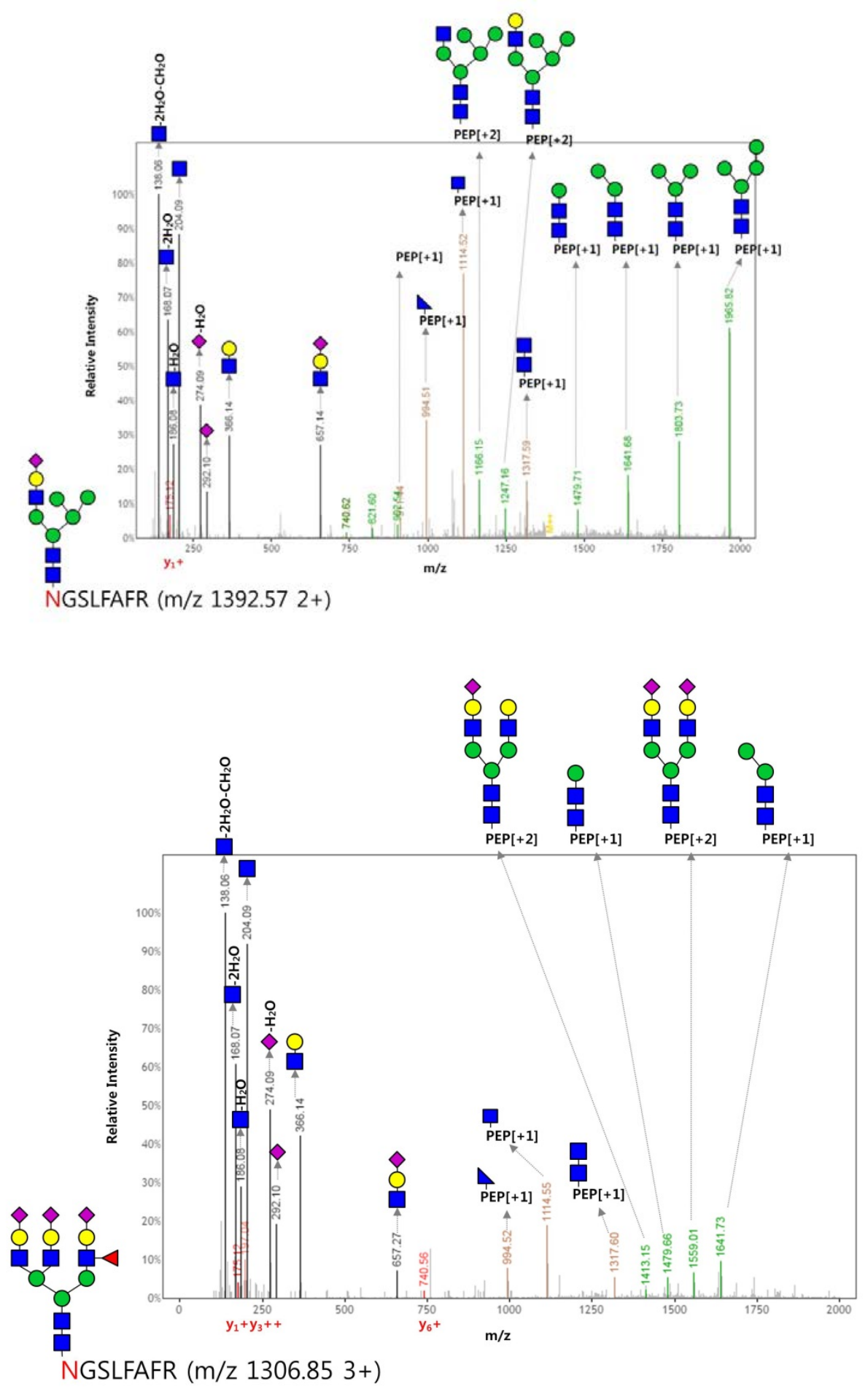

Figure S3. Differently identified N-glycopeptides from an HCC Human serum sample. Glycan symbols follow CFG nomenclature. $\quad$ means cross-ring cleavage fragments of GlcNAc with a loss of 120.0423 Da. 


\section{Figure S4}
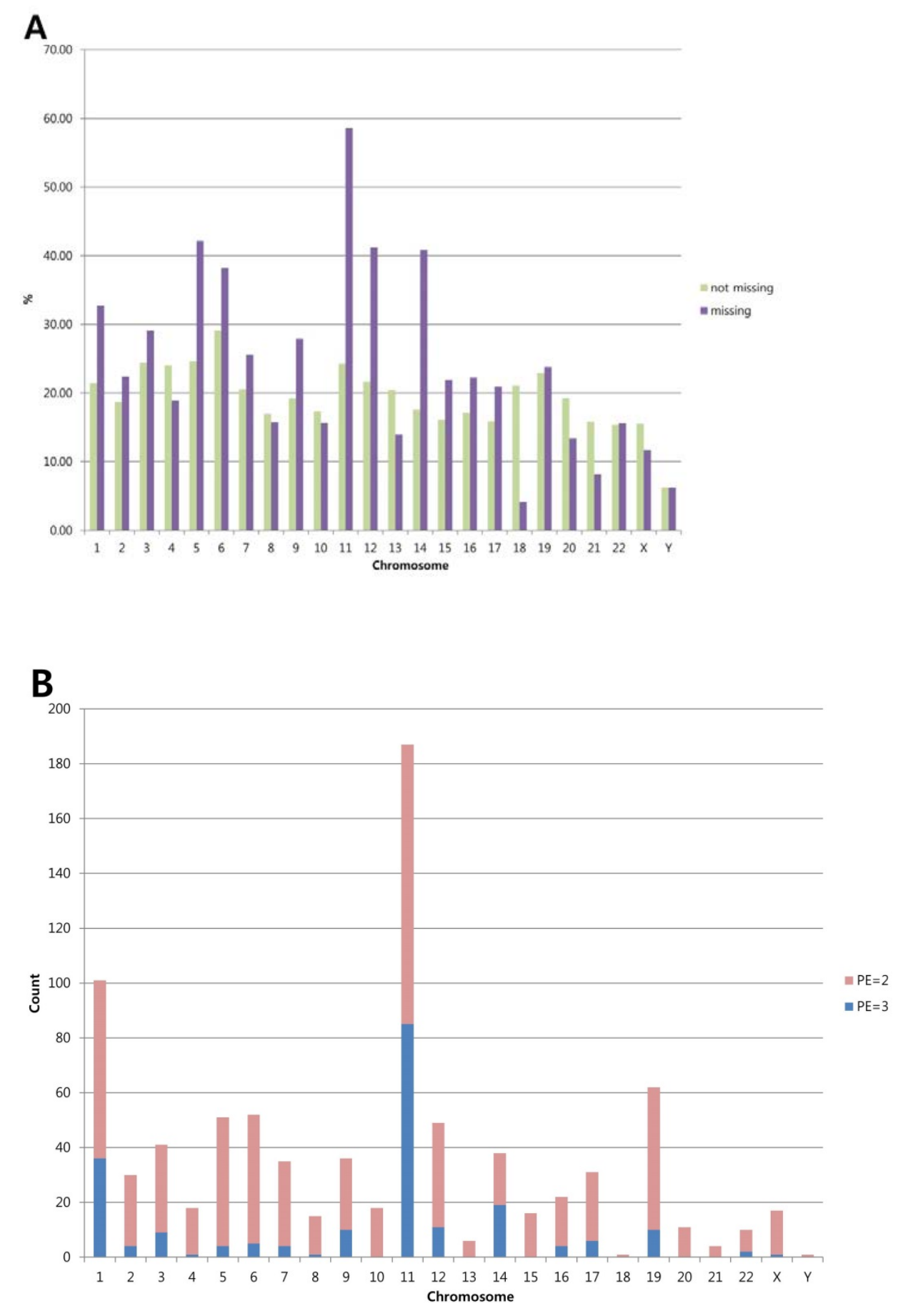

Figure S4. (A) Ratio of N-linked glycoprotein in human chromosomes. (B) Distribution of missing proteins containing N-linked glycosylation present in human chromosomes (UniProt release 2016_02). 


\section{Checklist for MS data}

\begin{tabular}{|c|c|}
\hline & General Guidelines: \\
\hline$\sqrt{ }$ & 1. Complete this HPP Data Interpretation Guidelines checklist and submit with the manuscript. \\
\hline NA & $\begin{array}{l}\text { 2. Submit all MS proteomics data (DDA, SRM, DIA), including analysis reference files (search database, spectral } \\
\text { library) to a ProteomeXchange repository as a complete submission and provide the PXD identifier(s) in the } \\
\text { manuscript abstract. }\end{array}$ \\
\hline$\sqrt{ }$ & $\begin{array}{l}\text { 3. Perform informatics analysis against the most recent version of the neXtProt reference proteome, particularly } \\
\text { with respect to potential missing proteins. }\end{array}$ \\
\hline$\sqrt{ }$ & 4. Describe in detail how the FDRs at the PSM, peptide, and protein levels are calculated. \\
\hline$\sqrt{ }$ & $\begin{array}{l}\text { 5. Report the PSM-, peptide-, and protein-level FDR values along with the total number of expected true } \\
\text { positives and false positives at each level. }\end{array}$ \\
\hline NA & led at equal to or lower than $1 \%$ protein-level global FDR. \\
\hline NA & $\begin{array}{l}\text { 7. Acknowledge that the protein-level FDR is an estimate based on several imperfect assumptions, and present } \\
\text { the FDR with appropriate precision. }\end{array}$ \\
\hline NA & 8. Acknowledge that not all proteins surviving the threshold are "confidently identified". \\
\hline NA & $\begin{array}{l}\text { 9. If any datasets are individually thresholded and then combined, calculate the new, higher FDR for the } \\
\text { combined result. }\end{array}$ \\
\hline \multicolumn{2}{|r|}{ Guidelines for extraordinary detection claims (e.g., missing proteins, novel coding elements) } \\
\hline NA & $\begin{array}{l}\text { 10. Present extraordinary detection claims based on DDA mass spectrometry with high-resolution, high signal-to- } \\
\text { noise ratio (SNR), clearly annotated spectra. }\end{array}$ \\
\hline NA & 11. Consider alternate explanations of PSMs that appear to implicate extraordinary results. \\
\hline NA & $\begin{array}{l}\text { 12. Present annotated spectra for extraordinary detection claims alongside high-resolution, high-SNR, clearly } \\
\text { annotated spectra of synthetic peptides that match the putative identifications. }\end{array}$ \\
\hline NA & $\begin{array}{l}\text { 13. If SRM verification for extraordinary detection claims is performed, present target traces alongside synthetic } \\
\text { heavy-labeled peptide traces, demonstrating very closely matching elution time and intensity patterns. }\end{array}$ \\
\hline NA & $\begin{array}{l}\text { 14. When very high confidence peptide identifications are demonstrated, consider alternate mappings of the } \\
\text { peptides to proteins other than the claimed extraordinary result. Consider isobaric sequence/mass modification } \\
\text { variants, all known SAAVs, and even unknown SAAVs. }\end{array}$ \\
\hline NA & $\begin{array}{l}\text { 15. Support extraordinary detection claims by two or more distinct uniquely-mapping peptide sequences of length } \\
\geq 9 \text { AA. When weaker evidence is offered for an extraordinary protein or coding element detection, justify that } \\
\text { other peptides cannot be expected. }\end{array}$ \\
\hline
\end{tabular}

\section{Author comments}

2. This manuscript does not contain its own MS dataset relevant to this checklist.

4-5. It is not applicable to our case where calculation of FDR is not possible because decoy is not available. However, we obtained a false positive rate for oxonium ion filtering and performed manual validation.

6-8. Our work is not applicable to the protein level ID.

10-15. This work simply provides clues for the missing proteins which contain N-linked glycopeptides instead of claiming the missing proteins. 